\title{
CONVERGENCE OF CHINA'S AGRICULTURAL GREENHOUSE GASES
}

\author{
LI, N. ${ }^{*}$ - LI, Y. M. - MU, H. L. - ZHANG, P. P. - JIANG, Y. Q. \\ Key Laboratory of Ocean Energy Utilization and Energy Conservation of the Ministry of \\ Education, Dalian University of Technology, Dalian, Liaoning 116024, China \\ *Corresponding author \\ e-mail:nanliln@yeah.net
}

(Received 23 $3^{\text {rd }}$ Apr 2019; accepted $11^{\text {th }}$ Jul 2019)

\begin{abstract}
Agriculture has become an important source of greenhouse gas emissions. This paper calculates the agricultural GHGs emissions of 30 provinces in China from 1997 to 2016, and analyzes the emission intensity of GDP of carbon dioxide, methane and nitrous oxide by club convergence. After using the DEA CCR model to divide the club, the absolute $\beta$-convergence analysis method is used to verify the emission trends of various greenhouse gases. The results showed that the carbon dioxide emission intensity showed obvious absolute $\beta$ convergence in all three clubs. Methane and nitrous oxide only have absolute $\beta$ convergence in one of the clubs, respectively, and there is divergence in other clubs. Since the emission trends of the three greenhouse gases in the clubs are different, the formulation of reasonable reduction target allocation plan should be more detailed and targeted, and more stringent emission reduction targets should be set for provinces with high GHGs intensity of GDP in order to reduce it rapidly.
\end{abstract}

Keywords: greenhouse gases, agriculture, convergence carbon dioxide, methane, nitrous oxide, emission reduction, climate policy

\section{Introduction}

China is a large agricultural country and the earliest origin of crop and farming culture. Since the 1980s, the annual growth rate of Chinese agriculture has been at the forefront of the world. In 1978-2008, agricultural growth increased by an average annual growth rate of $4.6 \%$. At the same time, agriculture has become a significant source of greenhouse gases. SAIN (China-UK Sustainable Agriculture Innovation Network, www.sainonline.org) reported that Chinese agriculture-related GHGs emissions accounted for $17 \%-20 \%$ of the total GHGs in the atmosphere, a ratio above the world average. In order to realize China's emission reduction commitments at the World Climate Conference in Paris, agricultural GHGs emission reduction has become the direction and inevitable trend of agricultural development in the future.

Carbon dioxide, methane and nitrous oxide are the most GHGs emitted in agricultural activities, and they are hot spots of research. Agricultural $\mathrm{CO}_{2}$ flux is mainly derived from the combustion of fossil fuels, the respiration of plant roots and decomposition of organic matter. Agriculture is the source and sink of $\mathrm{CO}_{2}$ (Zhang and Liang, 2011). Lal (2004) pointed out that global agricultural carbon sinks were down to $50 \%$ to $66 \%$ in history. Norse (2012) put forward that in the process of agricultural production of $\mathrm{CO}_{2}$ mainly by agricultural, agricultural machinery, agricultural irrigation and agricultural straw burning. Lelieveld et al. (1998) showed that biological processes produce about $70 \%$ of agricultural $\mathrm{CH}_{4}$. Yang et al. (2003) advised that the main sources of agricultural $\mathrm{CH}_{4}$ were rice fields, wetlands, sediments, intestinal fermentation, and animal manure treatment. Li et al. (2009) used GAINS model to predict the $\mathrm{N}_{2} \mathrm{O}$ emissions of Chinese 
agriculture. The results showed that the emissions would reach about 2 million $t$ in 2030, an increase of $31 \%$ compared with 2000 . Agricultural $\mathrm{N}_{2} \mathrm{O}$ emission mainly comes from agricultural land, fertilizer application and animal manure management.

It can be seen that agricultural GHGs has been a hot issue in research, and its emissions should not be underestimated. So it has far-reaching significance for the accounting of China's agricultural GHGs emissions and emission intensity.

Regional convergence was proposed in the middle of the 20th century, and the empirical research was based on the Solow growth model. The results of the study within the neoclassical framework show that backward areas present a "catch-up effect" relative to advanced areas. In 1986, Baumol (1986) first proposed the hypothesis of regional convergence. Barro and Salaimartin (Barro and Salaimartin, 1992; Barro and Mankiw, 1995; Salaimartin, 1996) put forward the theory of $\sigma$ convergence and $\beta$ convergence.

Since regional convergence theory can give policy implications, some scholars have used this theory to study greenhouse gas emissions, but most of the research does not involve agricultural greenhouse gas emissions. Huang (2013) used the spatio-temporal dynamic convergence model to analyze the per capita carbon dioxide emissions of Chinese cities from 1985 to 2008. Hao (2015) studied the carbon dioxide emission intensity of 29 provinces in China from 1995 to 2011, and proved that there was absolute $\beta$ convergence. Yang (2016) estimates total factor productivity from the perspective of whether there are environmental constraints, and examines the impact of carbon dioxide emissions on economic convergence in China's provinces. Robalino-Lopez (2016) studied the per capita carbon dioxide emissions of 10 South American countries from 1980 to 2010, and analyzed the convergence process of the per capita carbon dioxide emissions of these countries. Zang (2018) analyzed the per capita carbon dioxide emission convergence of 201 countries from 2003 to 2015, and calculated that the global per capita carbon emission convergence rate was less than $1 \%$ per year. Kouretas (2018) studied the convergence of energy consumption and carbon dioxide emission intensity in 23 European countries from 1970 to 2010 with the method of distribution dynamics, and the results showed that there was no convergence. Yu (2018) conducted a convergent analysis on the carbon intensity of China's industrial sector from 1995 to 2015, showing the existence of the condition convergent. The club convergence has also been used to study the issue of greenhouse gas emissions. The study of Jobert (2010) confirmed the convergence of European per capita carbon dioxide emissions. Based on China's provincial carbon intensity data from 1995 to 2011, Wang (2014) found that there was a significant divergence in carbon intensity at the national level by using logt test. Burnet (2016) studies the convergence of carbon dioxide emissions related to energy consumption across U.S. states between 1960 and 2010, forming a convergence club and two divergence groups. Apergis (2017) analyzed the carbon dioxide emissions of various states, and found empirically that there was no overall convergence of carbon dioxide emissions per capita in the United States. Liu (2018) studied the per capita emissions of industrial pollutants in 285 prefecture-level cities in China from 2003 to 2015, aiming to reveal the impact of industrial transfer on the formation of convergence clubs.

In this paper, the accounting of agricultural GHGs emissions and emission intensity is to understand the current situation of agricultural GHGs emissions in China more clearly. Because each club has a steady-state value of its emission intensity, the emission reduction share can be divided according to the decline rate of emission intensity. Therefore, the convergence analysis of agricultural GHGs emission intensity aims to 
provide a reference for the Chinese government to define the reduction target allocation plan.

\section{Methods}

\section{China's agricultural greenhouse gas emissions accounting}

China's agricultural GHGs accounting method refers to the means recommended by IPCC (www.ipcc.ch), Min (2012) research results and the Provincial GHGs Inventory Compilation Guide. Carbon dioxide is calculated mainly from the use of fossil fuels in agricultural production. Methane comes from rice paddies, ruminant intestinal fermentation and animal waste treatment. Nitrous oxide emissions calculated in this paper also mainly come from three parts, namely, crop soil background, fertilizer application and animal manure management. Then, this paper uses the GWP value recommended by IPCC to derive the agricultural GHGs emissions in China.

\section{Club convergence analysis}

Convergence is not a black or white issue; it presents a trend of narrowing the gap. In this paper, the intensity of agricultural greenhouse gas emissions in China is mainly verified by club convergence.

According to the energy value theory, for CCR model, the input factors include chemical energy, mechanical power energy, thermal energy and bio-energy input in agricultural production. The output factor is greenhouse gas emissions. The rate of intraclub convergence is calculated according to the absolute $\beta$ convergence regression equation.

$$
\frac{1}{t-t_{0}} \ln \frac{x_{t, i}}{x_{0, i}}=\alpha-\frac{1-e^{-\beta\left(t-t_{0}\right)}}{t-t_{0}} \ln x_{0, i}+\varepsilon_{t, i}
$$

where $\mathrm{x}_{\mathrm{t}, \mathrm{i}}$ and $\mathrm{x}_{0, \mathrm{i}}$ represent the intensity of agricultural GHGs emissions in the initial and final stages of the $\mathrm{i}$-th province, $\mathrm{t}$ represents the $\mathrm{t}$-year, $\mathrm{t}_{0}$ represents the initial, $\beta$ represents the convergence rate, $\alpha$ represents the intercept term, and $\varepsilon_{i, t}$ represents the error term. When there is a positive $\beta$ value, it indicates that there is absolute $\beta$ convergence in the intensity of agricultural greenhouse gas emissions in the club; conversely.

\section{Data}

The basic agricultural data are collected from the Statistical Yearbook of China, Husbandry/Energy/Agriculture Statistical Yearbook of China. The specific data are shown in Table 1.

\section{Results and discussion}

\section{Results of agricultural GHGs flux accounting in China}

The agricultural greenhouse gas emissions in China from 1997 to 2016 are shown in Figure la. GHGs emissions of $\mathrm{CO}_{2}$ equivalent are on the rise. In 1997, the flux was 
952.7404 $\mathrm{Tg} \mathrm{CO}_{2}$ e, and in 2016, it was $1031.5290 \mathrm{Tg} \mathrm{CO}_{2} \mathrm{e}$, with an average annual growth rate of $0.42 \%$.

Table 1. Data sources

\begin{tabular}{c|c}
\hline The relevant data & Source \\
\hline $\begin{array}{c}\text { Acreage of crops; the number of various animals; } \\
\text { China's agricultural GDP }\end{array}$ & Statistical Yearbook of China \\
\hline The number of livestock service number & Husbandry Statistical Yearbook of China \\
\hline $\begin{array}{c}\text { Agricultural employment data } \\
\text { production }\end{array}$ & Statistical Yearbooks of various provinces in China \\
\hline $\begin{array}{c}\text { Nitrogen fertilizer, phosphate fertilizer, potash } \\
\text { fertilizer, compound fertilizer, pesticide, plastic film } \\
\text { data }\end{array}$ & Agriculture Statistical Yearbook of China \\
\hline
\end{tabular}
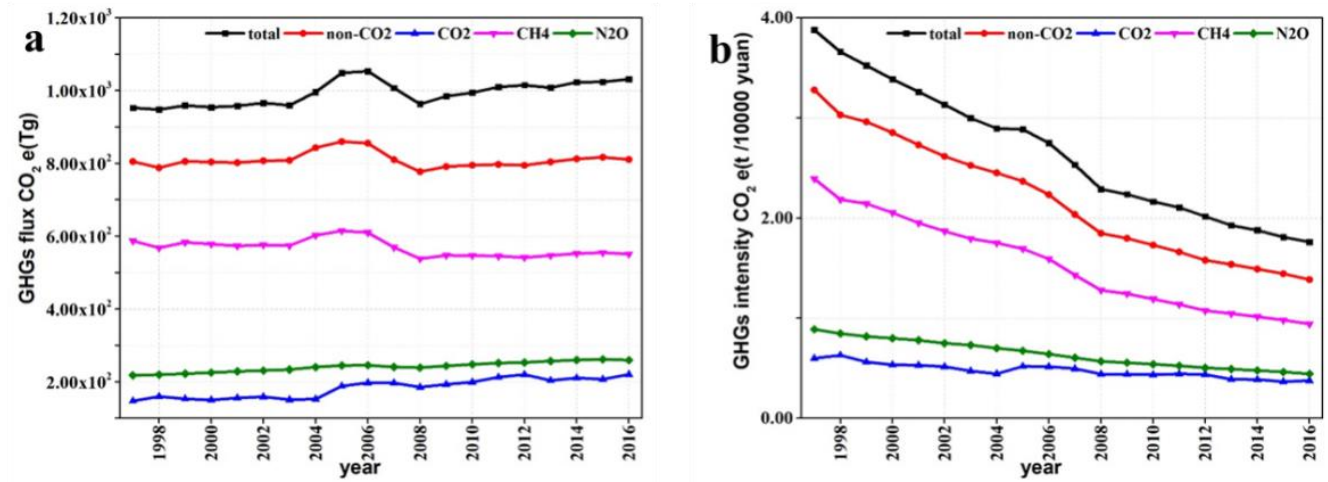

Figure 1. The agricultural GHGs flux in China from 1997 to 2016

Although agricultural GHGs flux in China shows an upward trend, the intensity of GDP declines obviously, almost linear (Fig. 1b). In 1997, the intensity was $3.8801 \mathrm{t} / 10,000$ yuan (about $2.6744 \mathrm{~kg} /$ dollar), in 2016, $1.7621 \mathrm{t} / 10,000$ yuan (about $1.2146 \mathrm{~kg} /$ dollar), the average annual decline rate was $4.24 \%$.

\section{Club convergence of agricultural GHGs intensity of GDP in China}

According to the CCR model of DEA, the total factor energy efficiency of each province from 1997 to 2016 is calculated, and the average value is counted, and the club is divided according to the average value of total factor energy efficiency. Because the object of the study is 30 provinces, in order to ensure that the number of data substituted into the convergence model and the number of club members are relatively average, the corresponding critical value is taken to divide the clubs. Since the output in the CCR model (agricultural GHGs flux of $\mathrm{CO}_{2}$ equivalent) is an undesired output, the lower efficiency value indicates that the situation of the region is more optimistic.

\section{Club convergence of $\mathrm{CO}_{2}$ intensity of GDP in China}

Agricultural carbon dioxide flux and emission intensity distribution are shown in Figure 2. Agricultural carbon dioxide flux show a certain geographical difference, the 
north is higher than the south, the middle and east are higher than the west. In particular, the provinces that gather in the Inner Mongolia-Guangdong axis have the largest flux. The distribution of $\mathrm{CO}_{2}$ intensity of GDP is also geographically different. The provinces with high intensity are concentrated in the northwest, and the intensity decreases from northwest to southeast.
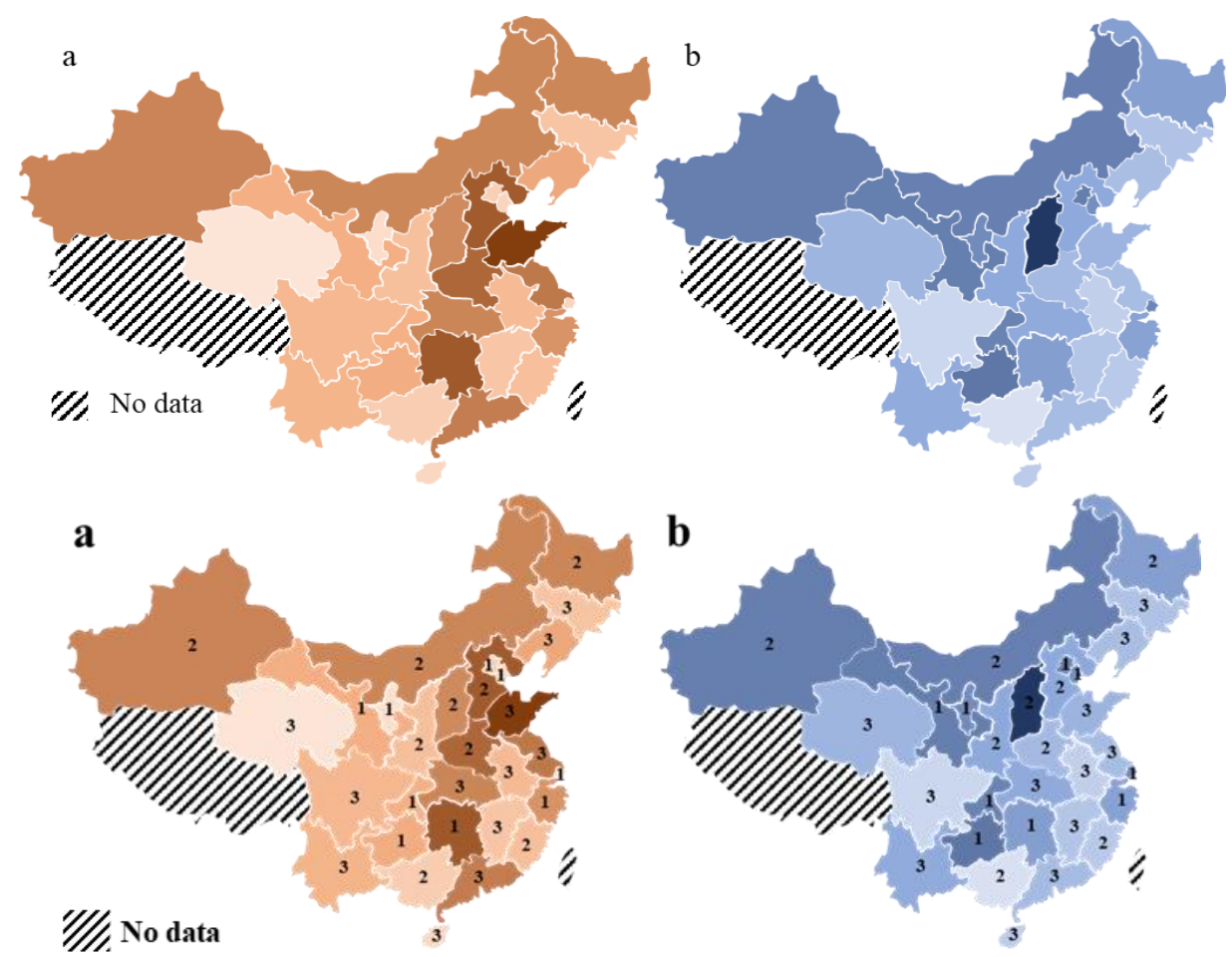

Figure 2. a Annual average flux of agricultural $\mathrm{CO}_{2}$ from 1997 to 2016. $\boldsymbol{b}$ Annual average $\mathrm{CO}_{2}$ intensity of GDP from 1997 to 2016. (Note: The color of each patch represents the size of its flux/intensity, where the darker the color, the greater the flux/intensity. The numbers 1, 2, and 3 indicate which club the area belongs to)

For the total factor energy efficiency of agricultural $\mathrm{CO}_{2}$ emission, a threshold of 0.78 and 0.90 will be set for each of the three national clubs (as shown in Fig. 3).

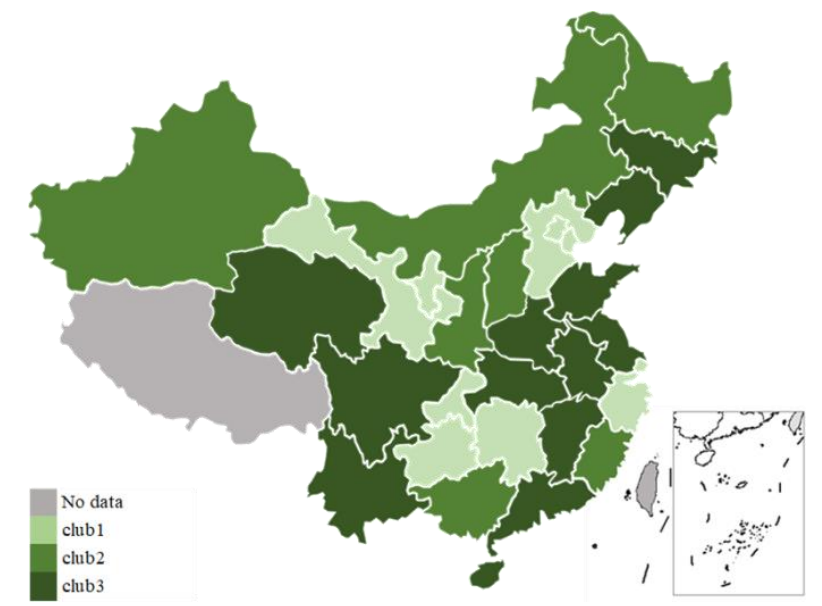

Figure 3. Club distribution of agricultural carbon dioxide intensity of GDP 
In the past 20 years, agricultural carbon dioxide flux of club 1 accounted for about $24.26 \%$ of the national agricultural carbon dioxide flux, and the proportion is decreasing year by year (Fig. 4a). The agricultural $\mathrm{CO}_{2}$ intensity of GDP was higher than other clubs, but the intensity declined at a higher rate, especially in Chongqing. As shown in Figure $4 b$, the strength of club 1 shows a downward trend, which also provides the possibility of verification of convergence. According to Equation 1, the calculation can obtain a positive $\beta$ value, that is, within club 1 , there is a significant absolute $\beta$ convergence of agricultural $\mathrm{CO}_{2}$ intensity, and the convergence rate is $15.55 \%$. The existence of this convergence phenomenon indicates that the difference in the emission intensity of the club members will gradually disappear, and the intensity will eventually reach the same stable value. In order to achieve the development of low carbon in agriculture quickly, the club 1 should follow the pattern of the convergence of members' $\mathrm{CO}_{2}$ intensity when designing reasonable reduction target allocation plan. Chongqing, Guizhou and Ningxia, where the emission intensity declines rapidly, should undertake heavier burden.
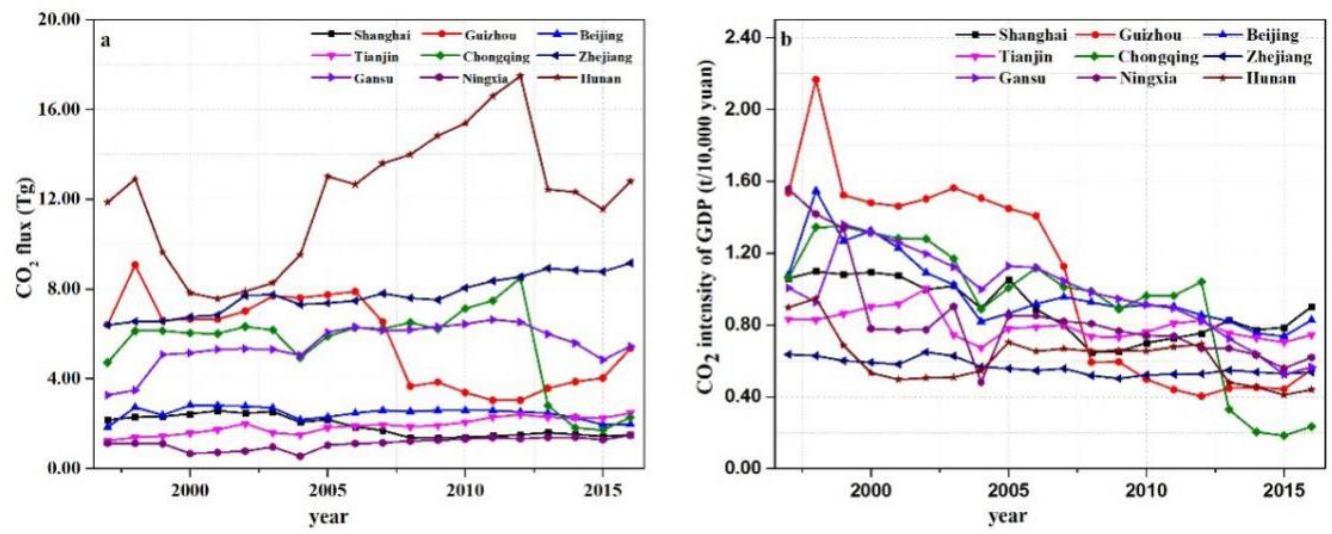

Figure 4. a Agricultural $\mathrm{CO}_{2}$ flux in club 1. $\boldsymbol{b}$ Agricultural $\mathrm{CO}_{2}$ intensity of GDP in club 1

From 1997 to 2016, the agricultural carbon dioxide flux of club 2 increased almost linearly (Fig. 5a). For the intensity of carbon dioxide, the reductions in Shanxi, Shaanxi and Henan are more obvious, and the intensity in Guangxi and Inner Mongolia is on the rise (Fig. 5b).
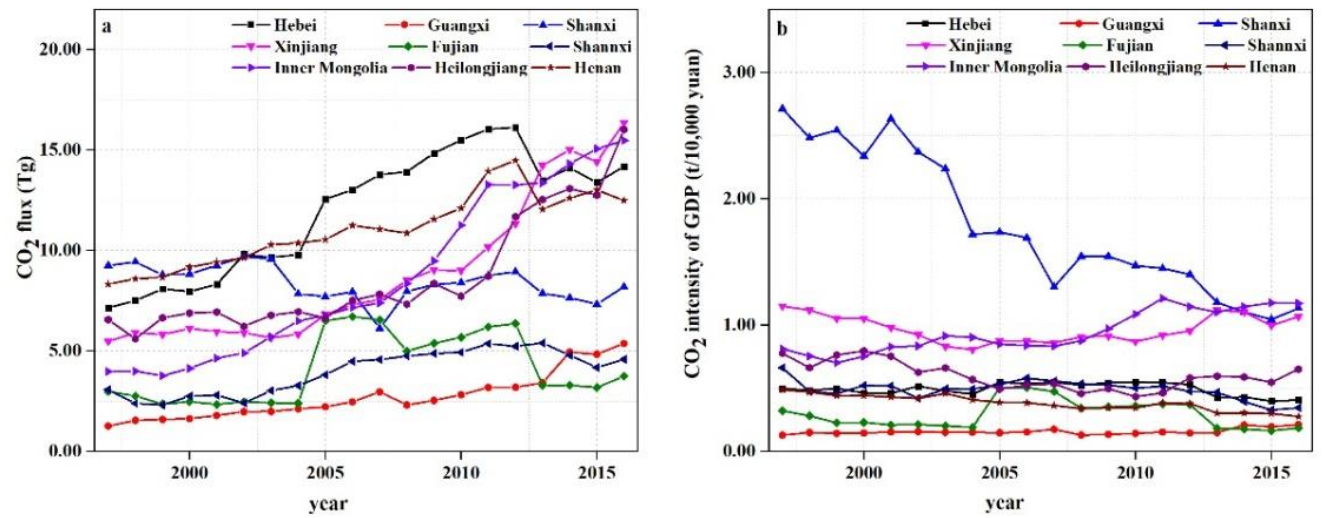

Figure 5. a Agricultural $\mathrm{CO}_{2}$ flux in club 2. b Agricultural $\mathrm{CO}_{2}$ intensity of GDP in club 2 
The absolute $\beta$ convergence rate of $\mathrm{CO}_{2}$ intensity of club 2 is $1.69 \%$. Members of club 2 are mostly energy-rich provinces. However, good resource endowments have made these places a rough way of using energy. At the same time, the economic development model of "energy dominates the economy" does not meet the requirements of sustainable development. Due to the special geographical and climatic conditions, Fujian and Guangxi have created distinctive subtropical agricultural farming methods, but the penetration rate of modern agricultural production methods is still low. Because of the absolute $\beta$ convergence, reduction allocation plan of club 2 should abide by the convergence model. Considering the rate of decline in emission intensity, Shaanxi and Shanxi should bear more emission reduction tasks. At the present stage, it is impossible to completely abandon coal, and the clean and intensive use of coal is a strategic choice.

The $\mathrm{CO}_{2}$ emission of club 3 is shown in the Figure 6. Club 3 is the group with the lowest carbon dioxide emission efficiency of agriculture. Its agricultural carbon dioxide flux accounts for $39.02 \%$ of the nation, and the ratio is decreasing. After calculation, the $\mathrm{CO}_{2}$ intensity of GDP of club 3 satisfies the absolute $\beta$ convergence condition, and the convergence rate is $5.08 \%$. Except for Qinghai, Sichuan, Yunnan and Hubei, members of club 3 are mostly in the eastern coastal or offshore areas. At the same time, Guangdong and Jiangxi have the largest decline in emission intensity, so they should take more responsibility for cutting $\mathrm{CO}_{2}$ emissions. As the members of this club are at the forefront of low-carbon development, it is a big problem to break the efficiency bottleneck.
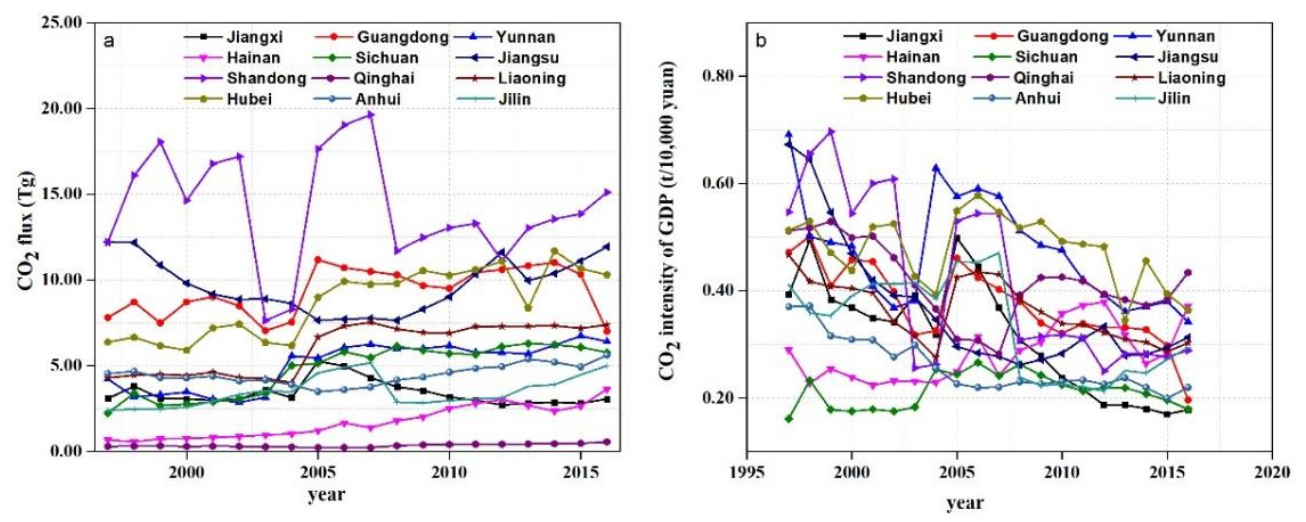

Figure 6. a Agricultural $\mathrm{CO}_{2}$ flux in club 3. $\boldsymbol{b}$ Agricultural $\mathrm{CO}_{2}$ intensity of GDP in club 3

The club convergence test results of agricultural $\mathrm{CO}_{2}$ intensity is shown in Table 2 . The decline of China's agricultural $\mathrm{CO}_{2}$ emission intensity shows the increase of agricultural energy efficiency. However, according to the efficiency value calculated by DEA, it shows that each region has certain emission reduction potential. In other words, from club1 to club3, the potential to reduce emissions is decreasing in turn. The key to $\mathrm{CO}_{2}$ emission reduction in China's agriculture is to adjust the structure of agricultural energy utilization and realize the clean utilization of coal.

\section{Club convergence of $\mathrm{CH}_{4}$ intensity of GDP in China}

The flux of methane from agricultural production is diverging from the two provinces of Shaanxi and Shanxi, and the flux is increasing (Fig. 7a). This is mainly because the animal husbandry and planting industry in Shaanxi and Shanxi provinces 
are not developed. The $\mathrm{CH}_{4}$ intensity of GDP in the Bohai Rim region is the lowest. The intensity in the north and south of the region is increasing (Fig. 7b).

Table 2. Club convergence test results of agricultural carbon dioxide intensity

\begin{tabular}{c|c|c|c}
\hline Test parameters & Club 1 & Club 2 & Club 3 \\
\hline$\alpha$ & -0.0301 & -0.0201 & -0.0503 \\
t-Statistic & -3.9575 & -2.2753 & -4.9670 \\
Prob. & 0.0055 & 0.0570 & 0.0006 \\
$\beta$ & 0.1555 & 0.0169 & 0.0508 \\
t-Statistic & -1.7534 & -1.5281 & -2.9682 \\
Prob. & $0.1230^{*}$ & 0.1703 & $0.0141^{* * *}$ \\
R2 & 0.3052 & 0.2501 & 0.4684 \\
\hline
\end{tabular}

$* * *, * *, *$ mean accepting the convergence hypothesis at $5 \%, 10 \%$ and $15 \%$ significance level
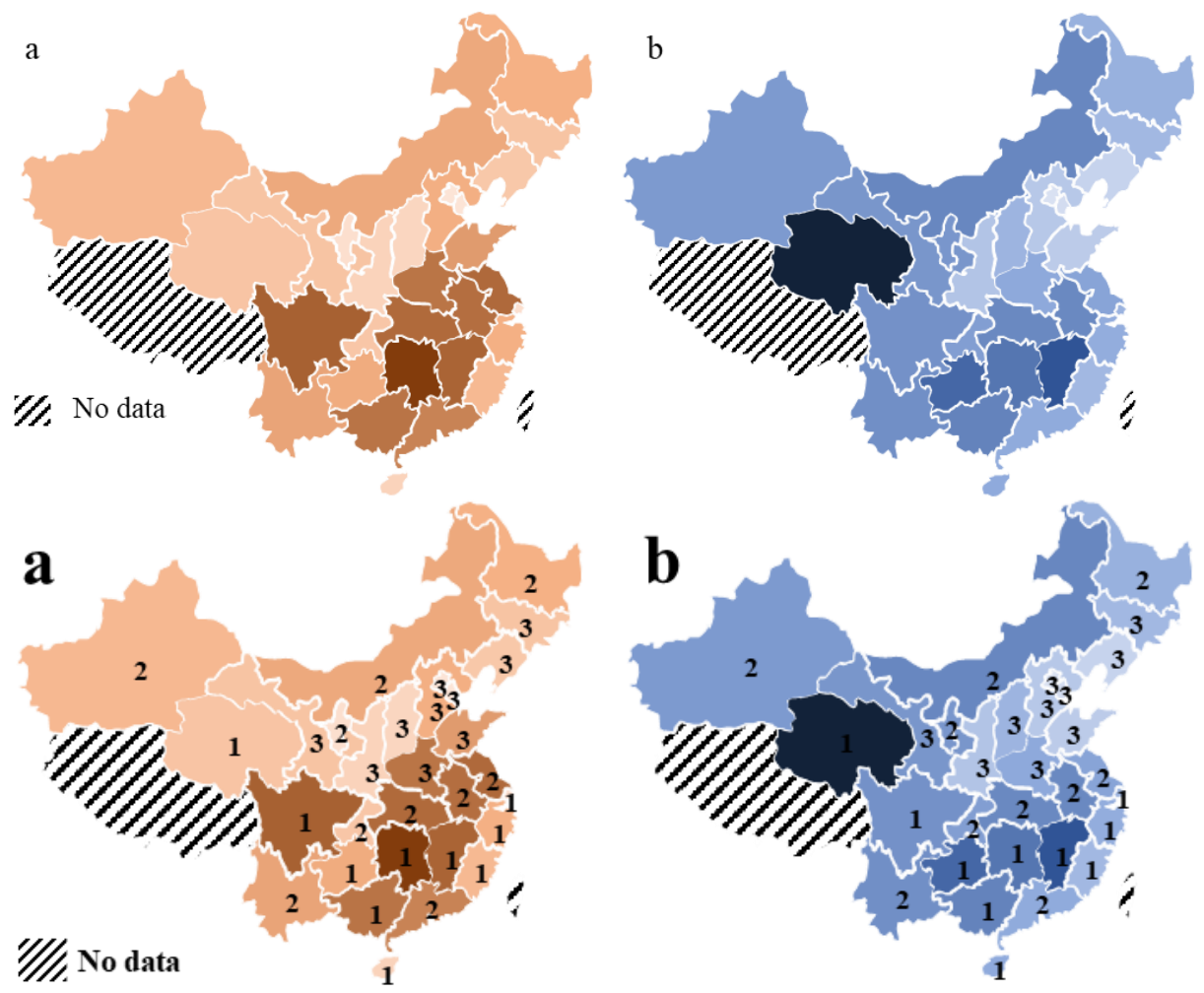

Figure 7. a Annual average flux of agricultural $\mathrm{CH}_{4}$ from 1997 to 2016. b Annual average $\mathrm{CH}_{4}$ intensity of GDP from 1997 to 2016. The numbers 1, 2, and 3 indicate which club the area belongs to

The average energy efficiency value calculated based on CCR model, with threshold values of 0.25 and 0.45 , the state is divided into three clubs. The distribution map is shown in Figure 8.

For club 1, please see Figure 9. In club $1, \mathrm{CH}_{4}$ emission intensity shows a downward trend, but there is no obvious convergence effect. Using Equation 1, a negative $\beta$ value is calculated. This is caused by large differences in the agricultural industrial structure 
of each member. Therefore, the formulation of reduction plan should fully consider the imbalance of the emission intensity of club members. As the prime rice producing area in China, club 1 plays a significant role in China's food security. For large rice planting provinces, the focus of emission reduction should be on the rice planting season. Qinghai and Hainan should increase agricultural input, improve agricultural technology and develop leisure agriculture. As for Shanghai, with its current urban orientation, the development of primary industry has a low cost performance, and it should focus on the development of other high-tech industries.

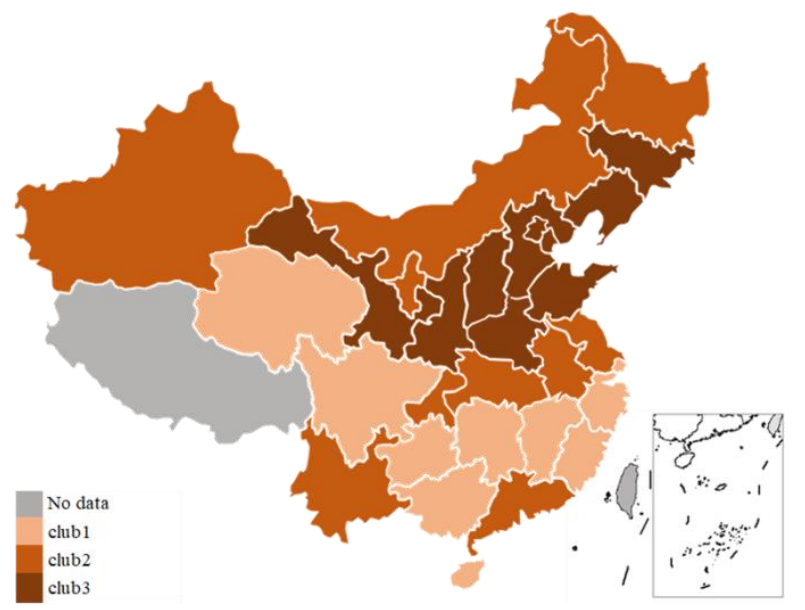

Figure 8. Club distribution of agricultural methane intensity of GDP
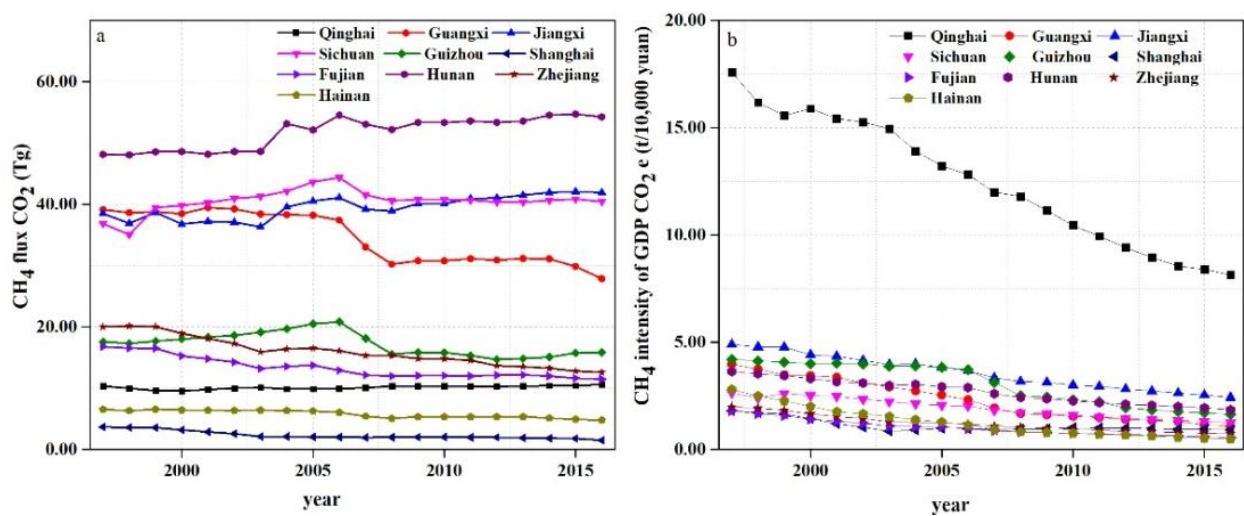

Figure 9. a Agricultural $\mathrm{CH}_{4}$ flux in club 1. $\boldsymbol{b}$ Agricultural $\mathrm{CH}_{4}$ intensity of GDP in club 1

Club 2 consists of seven major rice-growing provinces and three major livestock provinces. The club's agricultural $\mathrm{CH}_{4}$ flux is slightly less than club 1 (Fig. 10a), accounting for $39.00 \%$ of the total, mainly from rice fields and animal husbandry. The intensity of members in the club showed a downward trend (Fig. 10b), and the gap between the maximum and minimum emission intensity in 2016 is less than the difference in 1997. However, the narrowing of the two extremes does not indicate the overall convergence of emission intensity. After calculation, a negative $\beta$ value is obtained, that is, there is no absolute $\beta$ convergence. The formulation of the target allocation project of club 2 should focus on two points, namely, animal husbandry and 
rice field. Only by considering these two points can we create the optimal emission reduction effect.
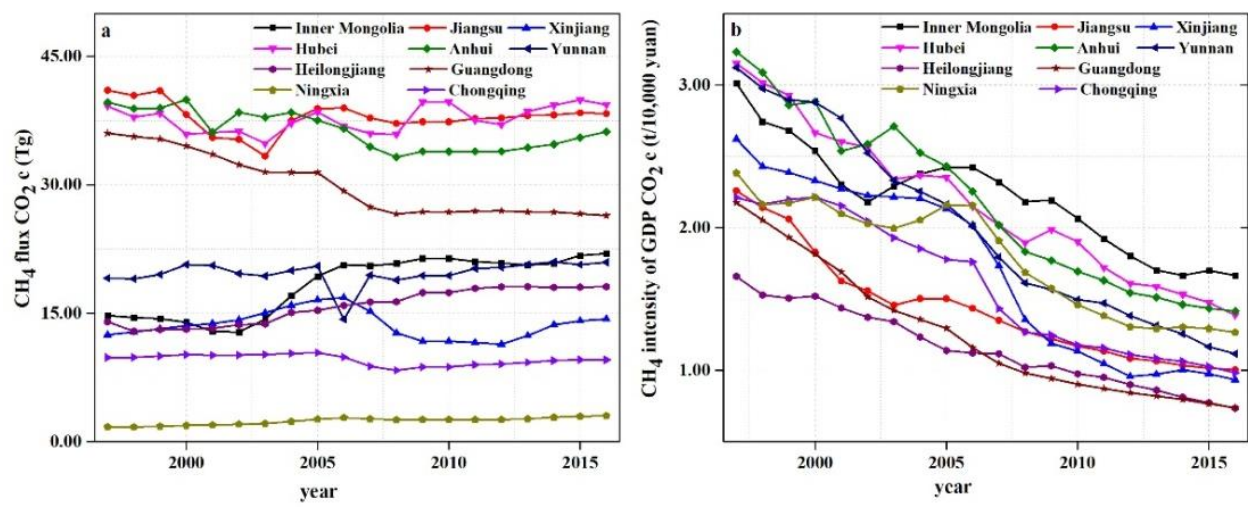

Figure 10. a Agricultural $\mathrm{CH}_{4}$ flux in club 2. $\boldsymbol{b}$ Agricultural $\mathrm{CH}_{4}$ intensity of GDP in club 2

Club 3 is the group with the lowest $\mathrm{CH}_{4}$ emission efficiency in agriculture, and with the lowest methane emissions, the lowest methane intensity. It can be seen from Figure $11 b$ that there is a clear downward trend of methane emission intensity. This is also verified on the model. After calculation, a positive $\beta$ value is obtained, indicating that the rate of absolute $\beta$ convergence is $2.19 \%$. Similar agricultural bases and development patterns are the dominant factors of the convergence. Shanxi, Henan, Gansu, and Shaanxi, which have the highest rate of decline in emission intensity, should be allocated a larger share of $\mathrm{CH}_{4}$ reduction. These regions have greater reduction potential than those with lower reduction rates such as Beijing and Liaoning.
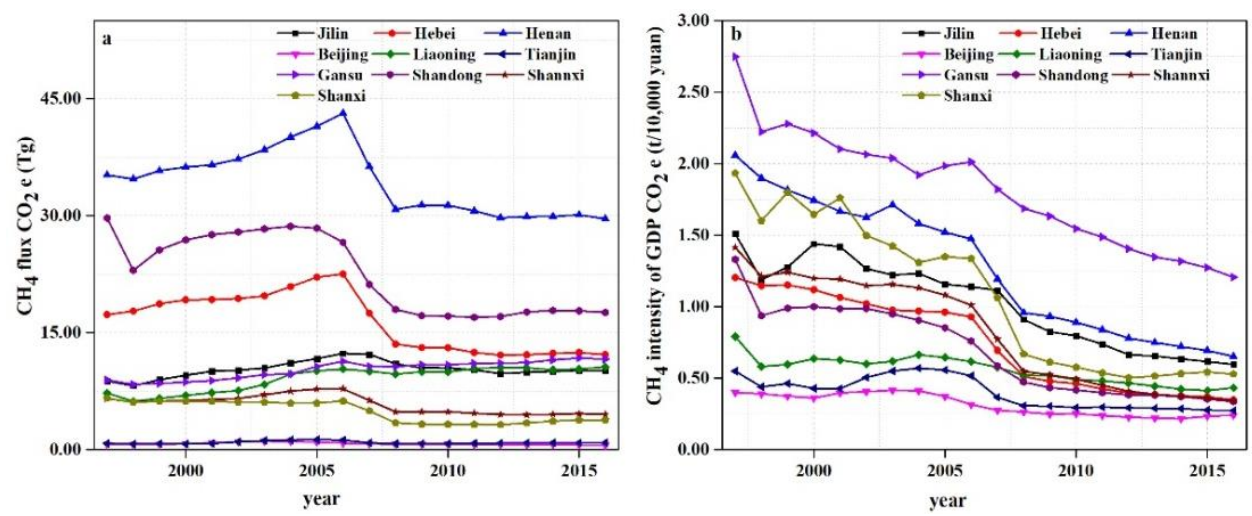

Figure 11. a Agricultural $\mathrm{CH}_{4}$ flux in club 3. $\boldsymbol{b}$ Agricultural $\mathrm{CH}_{4}$ intensity of GDP in club 3

$\mathrm{CH}_{4}$ clubs are classified similarly to $\mathrm{CO}_{2}$, with the most efficient club 1 having the greatest potential to reduce emissions. The main source of $\mathrm{CH}_{4}$ is agriculture. $\mathrm{CH}_{4}$ emission reduction mainly lies in paddy fields and animal husbandry, so emission reduction policy formulation should pay attention to the mid-term sunning of paddy fields and fertilizer management. At the same time, the management of pastoral areas is particularly important. The number of grassland should be used to determine the number of livestock breeding, so as to avoid the ecological dead cycle of vulnerable 
areas like Qinghai. In addition, the club convergence test results of agricultural $\mathrm{CH}_{4}$ intensity is given in Table 3.

Table 3. Club convergence test results of agricultural methane intensity

\begin{tabular}{c|c|c|c}
\hline Test parameters & Club 1 & Club 2 & Club 3 \\
\hline$\alpha$ & -0.0580 & -0.0456 & -0.0494 \\
t-Statistic & -4.4246 & -3.4347 & -10.0059 \\
Prob. & 0.0022 & 0.0089 & 0.0000 \\
$\beta$ & -0.0053 & -0.0012 & 0.0219 \\
t-Statistic & 0.6002 & 0.0900 & -2.1846 \\
Prob. & 0.5650 & 0.9305 & $0.0604^{* *}$ \\
$\mathrm{R}^{2}$ & 0.0431 & 0.0010 & 0.3737 \\
\hline
\end{tabular}

$* * *, * *, *$ mean accepting the convergence hypothesis at $5 \%, 10 \%$ and $15 \%$ significance level

\section{Club convergence of $\mathrm{N}_{2} \mathrm{O}$ intensity of GDP in China}

Agricultural nitrous oxide flux is mainly concentrated in the developed provinces of the planting industry, and the overall emissions in the east are greater than those in the west (Fig. 12a). The nitrous oxide intensity of GDP shows a different distribution pattern. The emission intensity in the west is greater than that in the east, showing a decreasing law from west to east, which is mainly caused by the fact that the agricultural output value in the east is much higher than that in the west (Fig. 12b).
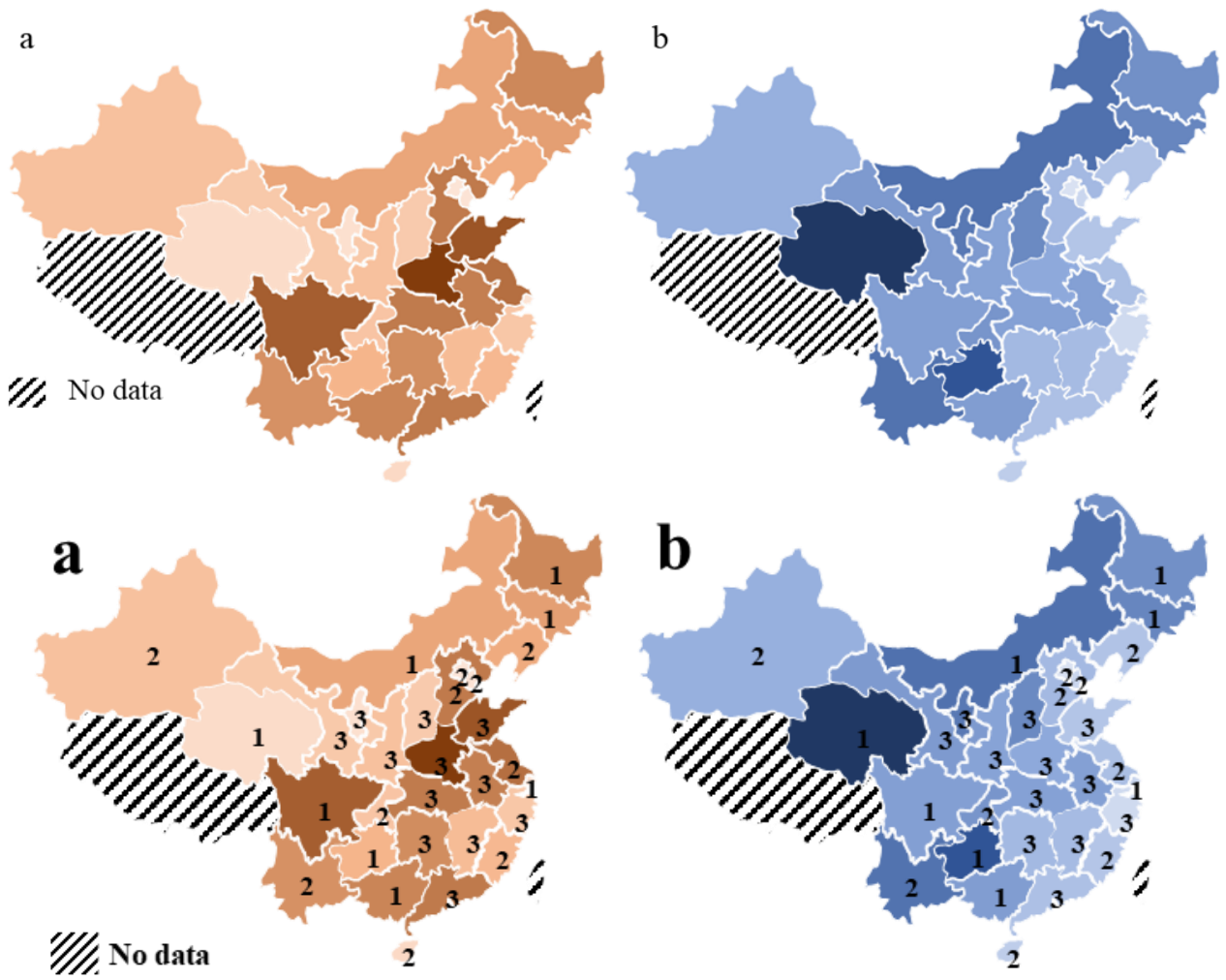

Figure 12. a Annual average flux of agricultural $\mathrm{N}_{2} \mathrm{O}$ from 1997 to 2016. $\boldsymbol{b}$ Annual average $\mathrm{N}_{2} \mathrm{O}$ intensity of GDP from 1997 to 2016. The numbers 1, 2, and 3 indicate which club the area belongs to 
For nitrous oxide, the club is divided in the same way. The energy efficiency values are divided into three intervals with 0.70 and 0.90 as the two critical values. This resulted in 3 clubs as shown in Figure 13.

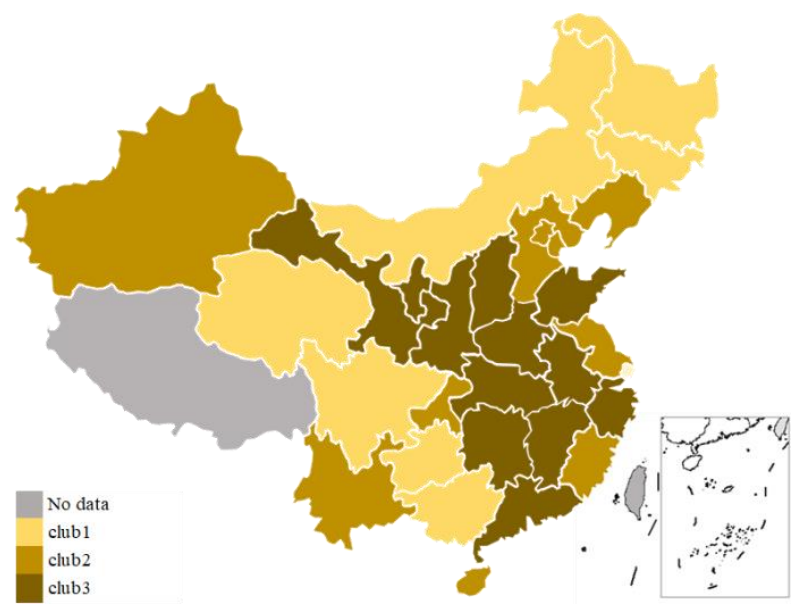

Figure 13. Club distribution of agricultural nitrous oxide intensity of GDP

The contradiction between people and land in the southwestern provinces of club 1 has intensified. In club 1, except for Shanghai, the agricultural $\mathrm{N}_{2} \mathrm{O}$ flux of all members shows an increasing trend (Fig. 14a). According to Equation 1, a positive $\beta$ value is calculated, which indicates that the absolute $\beta$ convergence rate of the first club is $1.02 \%$, that corresponds to Figure $14 b$. Agricultural $\mathrm{N}_{2} \mathrm{O}$ reduction policy of the club should be formulated in accordance with the convergence model. Qinghai should undertake more emission reduction tasks and should reduce Shanghai's emission reduction pressure.
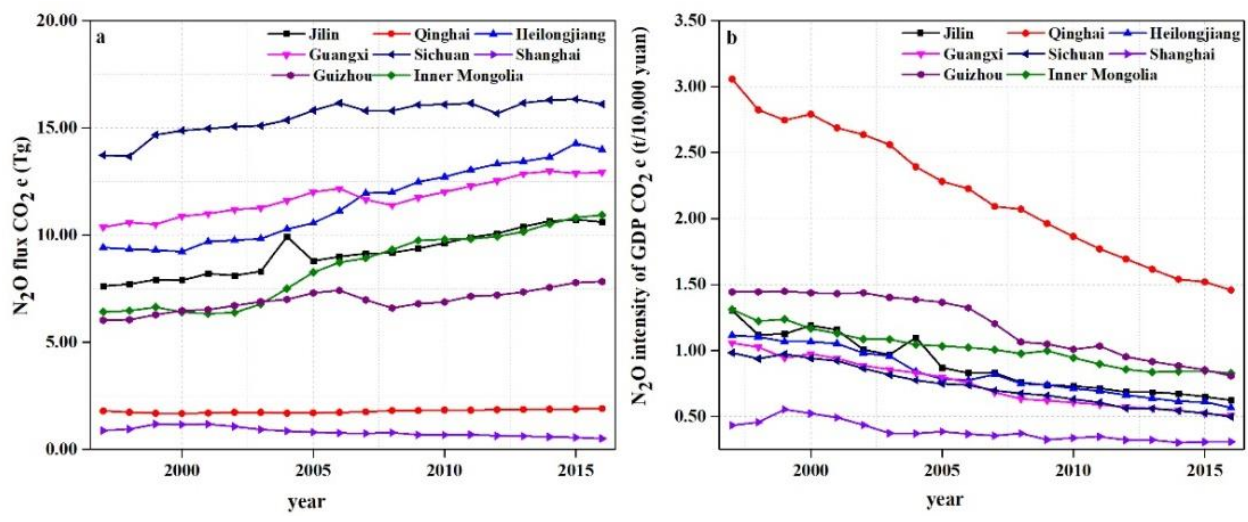

Figure 14. a Agricultural $\mathrm{N}_{2} \mathrm{O}$ flux in club 1. $\boldsymbol{b}$ Agricultural $\mathrm{N}_{2} \mathrm{O}$ intensity of GDP in club 1

The agricultural production of nitrous oxide flux is similar to club 1, but its emission intensity is only half of club 1 (Fig. 15b), which is mainly due to the fact that agricultural GDP of club 2 is much higher than club 1 . There is no absolute $\beta$ convergence in club 2 , which indicates that the $\mathrm{N}_{2} \mathrm{O}$ intensity of the members of the club will gradually increase, and its reduction target should be formulated according to 
the divergent model. That is, each member's emission reduction policy has different emphasis.
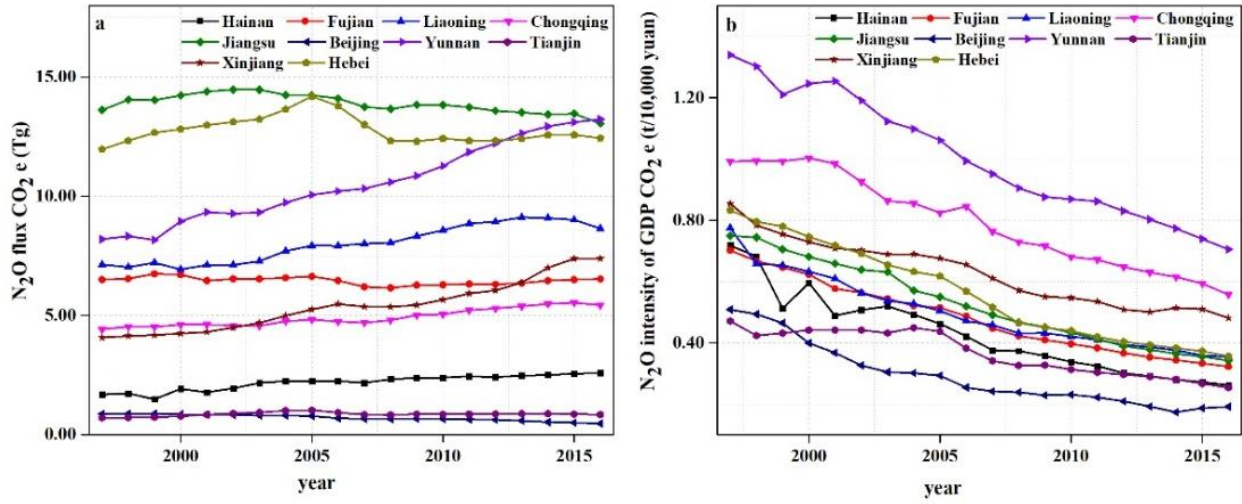

Figure 15. a Agricultural $\mathrm{N}_{2} \mathrm{O}$ flux in club 2. $\boldsymbol{b}$ Agricultural $\mathrm{N}_{2} \mathrm{O}$ intensity of GDP in club 2

Club 3 has the maximum number of members and the largest $\mathrm{N}_{2} \mathrm{O}$ flux (Fig. 16a). Although flux has declined in 2005-2008, the overall trend is increasing. The intensity of $\mathrm{N}_{2} \mathrm{O}$ of GDP within the club has decreased year by year and the gap has gradually constringed (Fig. 16b). A positive $\beta$ value is calculated, and the $\beta$ value is $0.17 \%$, but the value of $\mathrm{R}^{2}$ is only 0.0083 , that is, the credibility of absolute $\beta$ convergence is low. However, from Figure 16b, the narrowing of the difference in emission intensity seems to confirm the existence of the catch-up effect in the club.
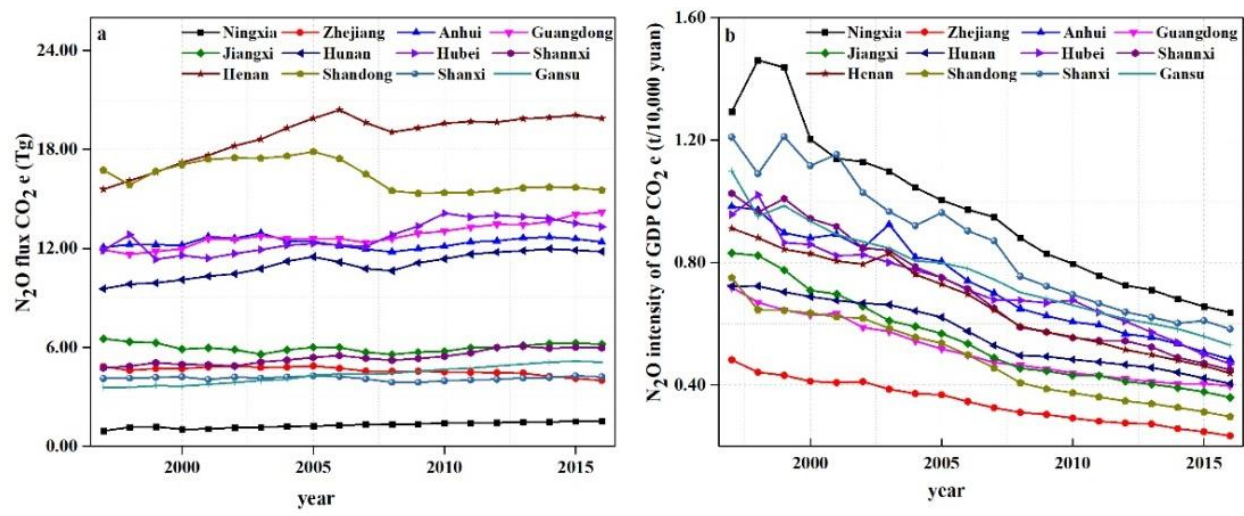

Figure 16. a Agricultural $\mathrm{N}_{2} \mathrm{O}$ flux in club 3. $\boldsymbol{b}$ Agricultural $\mathrm{N}_{2} \mathrm{O}$ intensity of GDP in club 3

Club 3 includes some crucial food production provinces, such as Shandong, Henan, Hunan, etc. The club plays an important role in ensuring Chinese food security. The SAIN another report pointed out that the excessive use of nitrogen fertilizer in cultivated wheat in Shaanxi reached $100 \%$, and the excessive application of nitrogen fertilizer in the land where tomatoes were grown in Shandong reached $80-200 \%$. According to the results of this study, club 3 has a huge potential for $\mathrm{N}_{2} \mathrm{O}$ emission reduction in fertilizer. Club 3 has many plains and abundant labor force, so it is necessary to deepen the agricultural industrial chain and promote the urbanization process. 
The club convergence test results of agricultural $\mathrm{N}_{2} \mathrm{O}$ intensity is listed in Table 4. Agricultural $\mathrm{N}_{2} \mathrm{O}$ mainly comes from planting industry. Based on the fact that China is a country with a large population, in order to feed more people on limited land, the agricultural input will be greatly increased, which will lead to the increase of $\mathrm{N}_{2} \mathrm{O}$ emissions. However, the increase of economic benefits brought by the increase of input is limited. Therefore, this agricultural economy dominated by large input is not the optimal agricultural development path and is not conducive to emission reduction. In order to reduce the emission of $\mathrm{N}_{2} \mathrm{O}$, it is necessary to control the amount of nitrogen fertilizer and plant nitrogen-fixing crops with high economic benefits.

Table 4. Club convergence test results of agricultural nitrous oxide intensity

\begin{tabular}{c|c|c|c}
\hline Test parameters & Club 1 & Club 2 & Club 3 \\
\hline$\alpha$ & -0.0376 & -0.0370 & -0.0388 \\
t-Statistic & -9.3643 & -10.5791 & -23.0593 \\
Prob. & 0.0001 & 0.0000 & 0.0000 \\
$\beta$ & 0.0102 & -0.0096 & 0.0017 \\
t-Statistic & 1.0587 & 1.1839 & -0.2896 \\
Prob. & 0.3305 & 0.2704 & 0.7780 \\
R $^{2}$ & 0.1574 & 0.1491 & 0.0083 \\
\hline
\end{tabular}

$* * *, * *, *$ mean accepting the convergence hypothesis at $5 \%, 10 \%$ and $15 \%$ significance level

\section{Conclusion}

GHGs reduction can bring co-benefits for air quality and human health (West et al., 2013), and has become the mainstream trend of economic development in various countries. The exploration of agricultural low-carbon development is a key area for scholars from all over the world.

The results of the club analysis show that the intensity of carbon dioxide in agriculture is in club convergence, and the absolute $\beta$ convergence rate of club 1 is $15.55 \%$, club 2 is $1.69 \%$, and club 3 is $5.08 \%$. Therefore, the emission reduction policy of carbon dioxide should be formulated according to the convergence model within the club. The two greenhouse gases, methane and nitrous oxide, only have convergence in one club. The methane emission intensity only converges at club 3 , and the absolute $\beta$ convergence rate is $2.19 \%$. The nitrous oxide emission intensity only converges in club 1 , and the absolute $\beta$ convergence rate is $1.02 \%$. Therefore, the emission reduction mode of these two gases should not only consider the convergence characteristics in the club, but also follow the divergence mode in the other two clubs.

The treatment of agricultural waste of resources, low level of mechanization of agriculture, agricultural pollution, and agricultural product safety are all issues that need to be addressed in the development of low-carbon agriculture (Peng and Liang, 2016). In view of the characteristics of China's agriculture, in order to achieve the development of low-carbon agriculture, it is necessary to improve the utilization efficiency of fossil fuels, explore more adaptable rice varieties and planting patterns, and promote more scientific animal farming techniques and nitrogen fertilizer application models. In particular, reducing the excessive use of nitrogen fertilizer will bring additional benefits, such as improving water quality, reducing soil acidification, enhancing air quality, increasing farmers' income, and improving the purchasing power 
of the rural economy (Zhang et al., 2013). At the same time, agriculture as an important carbon sink, its role in greenhouse gas emission reduction can not be ignored, which will be gradually advanced in future research.

Acknowledgements. The authors gratefully acknowledge the financial support from the National Natural Science Foundation of China (71603039). This research has also been supported by Fundamental Research Funds for the Central Universities (DUT18JC12).

\section{REFERENCES}

[1] Apergis, N., Payne, J. E. (2017): Per capita carbon dioxide emissions across US states by sector and fossil fuel source: evidence from club convergence tests. - Energ Econ 63: 365-372.

[2] Barro, R. J., Salaimartin, X. (1992): Regional growth and migration - a Japan-UnitedStates comparison. - J Jpn Int Econ 6: 312-346.

[3] Barro, R. J., Mankiw, N. G., Salaimartin, X. (1995): Capital mobility in neoclassical models of growth. - American Economic Review 85: 103-115.

[4] Baumol, W. J. (1986): Productivity growth, convergence, and welfare - what the long-run data show. - Am Econ Rev 76: 1072-1085.

[5] Burnett, J. W. (2016): Club convergence and clustering of US energy-related $\mathrm{CO}_{2}$ emissions. - Resour Energy Econ 46: 62-84.

[6] Hao, Y., Liao, H., Wei, Y. (2015): Is China's carbon reduction target allocation reasonable? An analysis based on carbon intensity convergence. - Appl Energ 142: 229239.

[7] Huang, B., Meng, L. (2013): Convergence of per capita carbon dioxide emissions in urban China: a spatio-temporal perspective. - Appl Geogr 40: 21-29.

[8] Jobert, T., Karanfil, F., Tykhonenko, A. (2010): Convergence of per capita carbon dioxide emissions in the EU: legend or reality? - Energ Econ 32: 1364-1373.

[9] Kounetas, K. E. (2018): Energy consumption and $\mathrm{CO}_{2}$ emissions convergence in European Union member countries. A tonneau des Danaides? - Energ Econ 69: 111-127.

[10] Lal, R. (2004): Soil carbon sequestration impacts on global climate change and food security. - Science 304: 1623-1627.

[11] Lelieveld, J., Crutzen, P. J., Dentener, F. J. (1998): Changing concentration, lifetime and climate forcing of atmospheric methane. - Tellus Series B-Chemical and Physical Meteorology 50: 128-150.

[12] Li, Y., Lin, E., Xiong, W. (2009): Modeling $\mathrm{N}_{2} \mathrm{O}$ emissions from agriculture in China. Progress in Geography 28: 636-642 (in Chinese).

[13] Liu, C., Hong, T., Li, H., Wang, L. (2018): From club convergence of per capita industrial pollutant emissions to industrial transfer effects: an empirical study across 285 cities in China. - Energ Policy 121: 300-313.

[14] Min, J., Hu, H. (2012): Calculation of greenhouse gases emission from agricultural production in china. - China Population, Resources and Environment 22: 21-27 (in Chinese).

[15] Norse, D. (2012): Low carbon agriculture: objectives and policy pathways. Environmental Development 1: 25-39.

[16] Peng, L., Liang, Y. H. (2016): Study on the Way to the Development of Low Carbon Agriculture in Henan Province. - In: Liu, X., Xu, G. (eds.) Advances in Social Science Education and Humanities Research. Atlantis Press, Paris.

[17] Robalino-Lopez, A., Garcia-Ramos, J. E., Golpe, A. A., Mena-Nieto, A. (2016): CO2 emissions convergence among 10 South American countries. A study of Kaya components (1980-2010). - Carbon Manag 7: 1-12. 
[18] Salaimartin, X. X. (1996): Regional cohesion: evidence and theories of regional growth and convergence. - Eur Econ Rev 40: 1325-1352.

[19] Wang, Y., Zhang, P., Huang, D., Cai, C. (2014): Convergence behavior of carbon dioxide emissions in China. - Econ Model 43: 75-80.

[20] West, J. J., Smith, S. J., Silva, R. A., Naik, V., Zhang, Y., Adelman, Z., Fry, M. M., Anenberg, S., Horowitz, L. W., Lamarque, J. (2013): Co-benefits of mitigating global greenhouse gas emissions for future air quality and human health. - Nat Clim Change 3: 885-889.

[21] Yang, J., Zhang, T., Sheng, P., Shackman, J. D. (2016): Carbon dioxide emissions and interregional economic convergence in China. - Econ Model 52: 672-680.

[22] Yang, S., Liu, C., Lai, C., et al. (2003): Estimation of methane and nitrous oxide emission from paddy fields and uplands during 1990-2000 in Taiwan. - Chemosphere 52: 12951305.

[23] Yu, S., Hu, X., Fan, J., Cheng, J. (2018): Convergence of carbon emissions intensity across Chinese industrial sectors. - J Clean Prod 194: 179-192.

[24] Zang, Z., Zou, X., Song, Q., Wang, T., Fu, G. (2018): Analysis of the global carbon dioxide emissions from 2003 to 2015: convergence trends and regional contributions. Carbon Manag 9: 45-55.

[25] Zhang, W., Dou, Z., He, P., Ju, X., Powlson, D., Chadwick, D., Norse, D., Lu, Y., Zhang, Y., Wu, L., Chen, X., Cassman, K. G., Zhang, F. (2013): New technologies reduce greenhouse gas emissions from nitrogenous fertilizer in China. - P Natl Acad Sci USA 110: 8375-8380.

[26] Zhang, Y., Hu, C., Zhang, J. (2011): Research advances on source/sink intensities and greenhouse effects of $\mathrm{CO}_{2}, \mathrm{CH}_{4}$ and $\mathrm{N}_{2} \mathrm{O}$ in agricultural soils. - Chinese Journal of EcoAgriculture 19: 966-975 (in Chinese). 